\title{
Tocilizumab in the treatment of systemic juvenile idiopathic arthritis
}

\author{
Miho Murakami' \\ Minako Tomiita ${ }^{2,3}$ \\ Norihiro Nishimoto' \\ 'Laboratory of Immune Regulation, \\ Wakayama Medical University, \\ Wakayama, ${ }^{2}$ Department of Pediatrics, \\ Graduate School of Medicine, Chiba \\ University, Chiba, ${ }^{3}$ Department of \\ Allergy and Rheumatology, Chiba \\ Children's Hospital, Chiba, Japan
}

Correspondence: Norihiro Nishimoto Laboratory of Immune Regulation, Wakayama Medical University, 105 Saito Bio Innovation Center 7-7-20, SaitoAsagi, Ibaraki-City, Osaka 567-0085, Japan Tel +8I7 26468039

Fax +81726468140

Email norichan@wakayama-med.ac.jp

\author{
This article was published in the following Dove Press journal: \\ Open Access Rheumatology: Research and Reviews \\ 4 July 2012 \\ Number of times this article has been viewed
}

\begin{abstract}
Systemic juvenile idiopathic arthritis is one of the common rheumatic diseases in childhood and characterized by spiking fever, evanescent skin rash, lymphadenopathy, hepatosplenomegaly, and serositis, in addition to arthritis. Children with systemic juvenile idiopathic arthritis often show growth retardation and developmental abnormality, as well as macrophage activation syndrome, a life-threatening complication. Overproduction of interleukin-6 is pathologically responsible for the systemic inflammatory manifestations and abnormal laboratory results with systemic juvenile idiopathic arthritis. Thus, tocilizumab, a humanized antihuman interleukin-6 receptor antibody, has been developed as a therapeutic agent for the disease. A series of clinical studies have demonstrated the excellent efficacy and safety of tocilizumab for patients with active disease. Tocilizumab was approved for systemic juvenile idiopathic arthritis in Japan in 2008 and in the European Union and the United States in 2011.
\end{abstract}

Keywords: systemic juvenile idiopathic arthritis, tocilizumab, antihuman interleukin-6 receptor antibody, biologics

\section{Introduction}

Juvenile idiopathic arthritis (JIA) is a collective term for a heterogeneous group of arthritides that begin before the age of 16 years, are sustained for more than 6 weeks, and are of unknown cause. ${ }^{1}$ According to the International League of Associations for Rheumatology classification criteria, JIA is divided into seven subtypes, ie, systemic arthritis, oligoarthritis, polyarthritis (rheumatoid factor-negative), polyarthritis (rheumatoid factor-positive), psoriatic arthritis, enthesitis-related arthritis, and undifferentiated arthritis. ${ }^{1}$ The classification of JIA and definitions of the seven subtypes are shown in Table 1. ${ }^{1}$ Systemic JIA is characterized by spiking fever, arthralgia or arthritis, myalgia, sore throat, evanescent rashes, lymphadenopathy, hepatosplenomegaly, and serositis that are distinct from the manifestations of the other JIA subtypes. Systemic JIA accounts for about $10 \%$ of JIA in North America and Europe; ${ }^{2}$ however, it is represented as the largest JIA subgroup in Japan, constituting 54\% of JIA. ${ }^{3}$ Therefore, the prevalence seems ethnicity-dependent. There is no age-specific or gender-specific incidence in this disease. ${ }^{4}$ Association with macrophage activation syndrome, which is a severe complication of systemic JIA, is another distinctive feature among the subtypes and increases the mortality risk in patients with systemic JIA. ${ }^{5}$ In addition, growth retardation and developmental abnormality are often observed in patients with systemic JIA, and physically and psychologically affect quality of life, both in childhood and after growth to adulthood. 
Table I Classification of juvenile idiopathic arthritis

\begin{tabular}{|c|c|c|}
\hline Classification & Definition & Exclusions \\
\hline Systemic arthritis & $\begin{array}{l}\text { Arthritis in one or more joints with or preceded by fever of at least } 2 \text { weeks' } \\
\text { duration that is documented to be daily ("quotidian”) for at least } 3 \text { days, } \\
\text { and accompanied by one or more of the following: } \\
\text { - Evanescent (nonfixed) erythematous rash } \\
\text { - Generalized lymph node enlargement } \\
\text { - Hepatomegaly and/or splenomegaly } \\
\text { - Serositis }\end{array}$ & $a, b, c, d$ \\
\hline Oligoarthritis & $\begin{array}{l}\text { Arthritis affecting } 1-4 \text { joints during the first } 6 \text { months of disease. } \\
\text { Two subcategories are recognized: } \\
\text { - Persistent oligoarthritis: affecting not more than } 4 \text { joints throughout } \\
\text { the disease course } \\
\text { - Extended oligoarthritis: affecting a total of more than } 4 \text { joints after } \\
\text { the first } 6 \text { months of disease }\end{array}$ & $\mathrm{a}, \mathrm{b}, \mathrm{c}, \mathrm{d}, \mathrm{e}$ \\
\hline Polyarthritis (RF-negative) & $\begin{array}{l}\text { Arthritis affecting } \geq 5 \text { joints during the first } 6 \text { months of disease; } \\
\text { a test for RF is negative }\end{array}$ & $a, b, c, d, e$ \\
\hline Polyarthritis (RF-positive) & $\begin{array}{l}\text { Arthritis affecting } \geq 5 \text { joints during the first } 6 \text { months of disease; } 2 \text { or more tests } \\
\text { for RF at least } 3 \text { months apart during the first } 6 \text { months of disease are positive }\end{array}$ & $a, b, c, e$ \\
\hline Psoriatic arthritis & $\begin{array}{l}\text { Arthritis and psoriasis, or arthritis and at least two of the following: } \\
\text { - Dactylitis } \\
\text { - Nail pitting or onycholysis } \\
\text { - Psoriasis in a first-degree relative }\end{array}$ & $b, c, d, e$ \\
\hline Enthesitis-related arthritis & $\begin{array}{l}\text { Arthritis and enthesitis, or arthritis or enthesitis with at least } 2 \text { of the following: } \\
\text { - Presence of or a history of sacroiliac joint tenderness and/or inflammatory } \\
\text { lumbosacral pain } \\
\text { - Presence of HLA B27 antigen } \\
\text { - Onset of arthritis in a male over } 6 \text { years of age } \\
\text { - Acute (symptomatic) anterior uveitis } \\
\text { - History of ankylosing spondylitis, enthesitis-related arthritis, sacroiliitis with inflammatory } \\
\text { bowel disease, Reiter's syndrome, or acute anterior uveitis in a first-degree relative }\end{array}$ & $\mathrm{a}, \mathrm{d}, \mathrm{e}$ \\
\hline Undifferentiated arthritis & Arthritis that fulfills criteria in no category or in two or more of the above categories & \\
\hline
\end{tabular}

Notes: aPsoriasis or a history of psoriasis in the patient or first-degree relative; barthritis in an HLA B27-positive male beginning after his sixth birthday; 'ankylosing spondylitis, enthesitis-related arthritis, sacroiliitis with inflammatory bowel disease, Reiter's syndrome, or acute anterior uveitis, or a history of one of these disorders in a first-degree

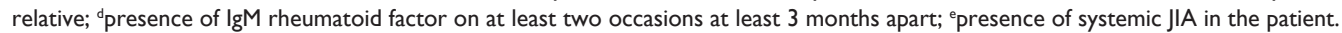

Data from Petty et al.'

Abbreviation: RF, rheumatoid factor; HLA, human leukocyte antigen.

Conventional therapies such as nonsteroidal antiinflammatory drugs alone or a combination with low to intermediate doses of corticosteroids and/or immune suppressants including methotrexate, have been used for JIA up until recently. However, most patients with systemic JIA are refractory to the conventional therapies and, therefore, require long-term use of high-dose corticosteroids to control their disease activity. These agents often cause deleterious side effects, including corticosteroid-induced growth retardation, osteoporosis, obesity, secondary diabetes, lipid abnormality, hypertension, hirsutism, cataract, and glaucoma. Therefore, other therapeutic options having high efficacy and safety have been eagerly awaited for children with systemic JIA.

Various cytokines have been reported to be involved in the pathogenesis of JIA, and they may be good targets to be inhibited for treatment of this disease. For example, the soluble tumor necrosis factor (TNF) receptor, etanercept, which specifically interferes with TNF functioning, has shown excellent results in treating patients with polyarticular JIA. ${ }^{6-13}$ However, the results of treatment with etanercept in patients with systemic JIA were unsatisfactory, ${ }^{13,14}$ although elevated levels of TNF in synovial fluid from patients with systemic JIA were observed. ${ }^{15,16}$ These disappointing clinical results indicate that TNF may not be a central player in systemic JIA. ${ }^{17}$ Furthermore, development of macrophage activation syndrome was reported in a patient with systemic JIA after initiation of etanercept therapy. ${ }^{18}$ Interleukin (IL)-1 is another candidate cytokine to be targeted for the treatment of systemic JIA. Anakinra, an IL-1 receptor antagonist, has been shown to be effective in patients with systemic JIA, ${ }^{19,20}$ but requires daily subcutaneous injection and consequently has poor tolerability.

IL-6 is considered to be another important cytokine, dysregulated overproduction of which plays a pathological role 
in immune inflammatory diseases, including systemic JIA, and is a candidate molecule to be inhibited by treatment. ${ }^{21}$ Tocilizumab is a humanized antihuman IL-6 receptor monoclonal antibody that specifically blocks IL-6 signaling and has been developed as a therapeutic agent for diseases involving pathological overproduction of IL-6. This review article describes the pathological role of IL-6 in systemic JIA, as well as the efficacy and safety of tocilizumab in treating patients with this refractory disease.

\section{Pathological roles of IL-6 in systemic JIA}

IL-6 is produced by various cell types, including T cells, B cells, monocytes, fibroblasts, keratinocytes, endothelial cells, and mesangial cells (Figure 1). This cytokine also influences various cell types and shows multiple biological activities, including key roles in immune regulation and the inflammatory response. IL-6 was originally identified as a $\mathrm{T}$ cell-derived $\mathrm{B}$ cell differentiation factor, which induces activated B cells to differentiate into antibody-producing cells. $^{22,23}$ IL-6, synergistically with IL-3, supports the formation of multilineage blast cell colonies. ${ }^{24}$ IL- 6 also induces proliferation of T cells via upregulation of the IL-2 receptor ${ }^{25}$ and differentiation of cytotoxic T cells. ${ }^{26}$ More recently, the pathological significance of $\mathrm{T}$ helper (Th) cells, known as
Th17 cells, that produce IL-17, IL-6, and TNF, but not IL-4 or interferon-gamma (IFN- $\gamma$ ) was focused on autoimmune and inflammatory diseases. This subset is distinct from Th1, which produces IFN- $\gamma$ and mediates cellular immunity, and Th2, which produces IL-4, IL-5, and IL-13 and mediates humoral immunity and allergic responses. ${ }^{27}$ Th17 cells, in the presence of IL-6, differentiate by stimulation of transforming growth factor-beta (TGF- $\beta$ ), while TGF- $\beta$ alone induces naturally occurring CD4+CD25+Forkhead box P3 (FOXP3)+ T regulatory (Treg) cells, which inhibit autoimmunity and inflammation. IL-6 is a key cytokine in these reciprocal developmental pathways for the generation of Th17 cells and Treg cells, although the pathological roles of Th17 cells in human diseases, especially in systemic JIA, are still obscure. IL-6 also induces megakaryocyte differentiation $^{28}$ and terminal macrophage differentiation, ${ }^{29}$ and is possibly involved in thrombocytosis and macrophage activation in systemic JIA. ${ }^{30}$

Overexpression of IL-6 is responsible for the systemic inflammatory manifestations of systemic JIA. IL-6 is an important regulator of hypothalamic-pituitary-adrenal axis hormones, ${ }^{31}$ and is possibly involved in the fatigue and anorexia seen in systemic JIA. Because in vivo administration of IL-6 causes leukocytosis and fever, ${ }^{32}$ leukocytosis and fever observed in systemic JIA appears to be IL-6-related. In

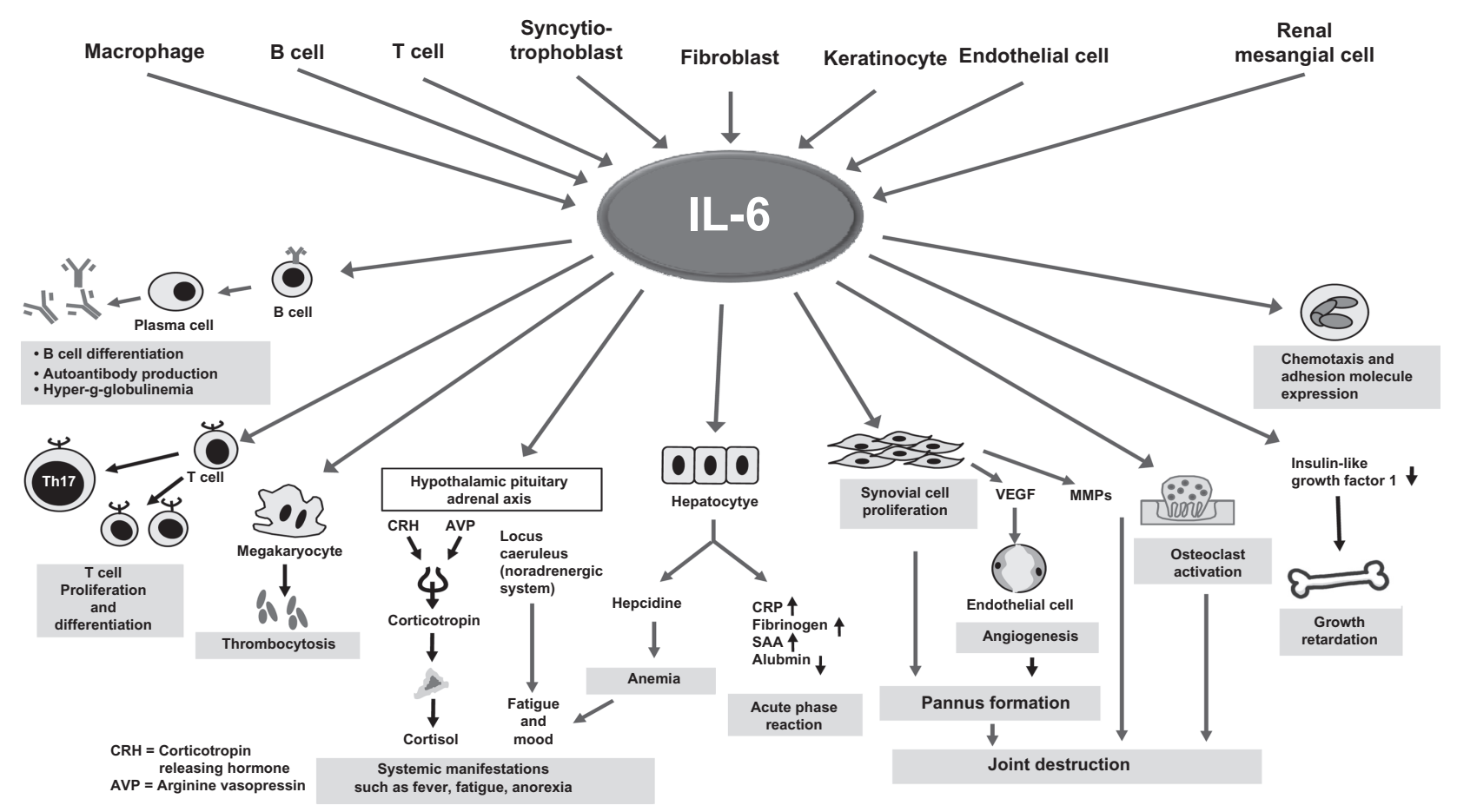

Figure I Multiple sources of interleukin-6 and its pleiotropic functions on various target cells.

Abbreviations: IL, interleukin; CRH, corticotrophin-releasing hormone; AVP, arginine vasopressin; CRP, C-reactive protein; SAA, serum amyloid A; VEGF, vascular endothelial growth factor; MMPs, matrix metalloproteinases. 
fact, the pattern of fever spikes was correlated with serum levels of IL-6 in patients with systemic JIA. ${ }^{33,34}$

Abnormal laboratory test results are typically seen in systemic JIA, and include increased C-reactive protein, erythrocyte sedimentation rate, white blood cell count, platelet count, and serum ferritin levels, in association with decreased hemoglobin levels. In the acute phase of the inflammation reaction, IL-6, as a hepatocyte stimulating factor, induces acute phase proteins such as C-reactive protein, fibrinogen, $\alpha 1$-antitrypsin, and serum amyloid A, and simultaneously suppresses albumin production. The production of these proteins is well correlated with serum IL-6 levels in patients with systemic JIA. ${ }^{33}$ IL-6 also induces secretion of hepcidin, an iron regulatory peptide hormone produced by hepatocytes which negatively regulates absorption of intestinal iron and iron recycling by macrophages. Therefore, excessive production of IL-6 leads to the hypoferremic anemia of inflammation. ${ }^{35}$ In addition, IL-6 can induce vascular endothelial growth factor, which plays a crucial role in the angiogenesis necessary for synovial pannus formation and causes joint destruction. ${ }^{36}$ Vascular endothelial growth factor also increases vascular permeability and causes inflammatory edema and the appearance of effusion. In bone metabolism, IL-6, in the presence of the soluble IL-6 receptor, induces osteoclast differentiation, ${ }^{37}$ thereby contributing to bone absorption which results in joint destruction and osteoporosis.

Growth retardation is another distinctive clinical feature of systemic JIA. Low serum levels of insulin-like growth factor-I, but not growth hormone, are observed in patients with systemic JIA ${ }^{38-40}$ and are possibly responsible for the growth retardation, although insulin-like growth factor-I levels are not always associated with growth rates $^{38}$ or z scores for height. ${ }^{39}$ IL-6 transgenic mice, which overproduce human IL-6, show growth retardation and have decreased insulin-like growth factor-I levels, ${ }^{40-43}$ strongly implicating IL-6 in growth retardation.

IL-6 is markedly elevated in both serum and the synovial fluid of patients with systemic JIA. ${ }^{33,44}$ Polymorphism in the promoter region of the $I L-6$ gene has been reported as a mechanism for augmented production of IL-6. A significant correlation has been observed between a $\mathrm{G} / \mathrm{C}$ polymorphism at position 174 of the IL6 gene and systemic JIA, so may result in enhanced IL-6 production in patients with the disease. ${ }^{45,46}$ This evidence has encouraged us to target IL-6 in the treatment of patients with systemic JIA refractory to conventional therapies.

\section{IL-6 receptor system and tocilizumab}

The IL- 6 signal is mediated by a unique receptor system which consists of two functional receptor components, ie, an $80 \mathrm{kDa}$ ligand-binding chain (IL-6 receptor, CD126) and a $130 \mathrm{kDa}$ nonligand-binding signal-transducing chain (glycoprotein [gp] 130, CD130). ${ }^{47}$ The soluble IL-6 receptor, which lacks the intracytoplasmic portion of the IL-6 receptor, is found in serum and body fluids, including synovial fluid. Unlike the soluble TNF receptor, which acts as an antagonist for TNF, the soluble IL-6 receptor acts as a ligand-binding receptor and is capable of signal transduction. This signaling mechanism, mediated by the soluble IL-6 receptor, is known as trans-signaling, whereby the IL- 6 signal can be transduced into cells as long as they express gp $130 .{ }^{48}$ When IL- 6 binds to the membrane-binding IL-6 receptor or soluble IL-6 receptor, the complex induces homodimerization of gp130 and forms a high-affinity functional receptor complex of IL-6, IL-6 receptor, and gp130. Tocilizumab binds to both the membrane-binding and soluble IL-6 receptor, and specifically blocks IL-6 binding to the IL-6 receptor (Figure 2).

\section{Efficacy and safety of tocilizumab in patients with systemic JIA}

Clinical studies of tocilizumab for systemic JIA were conducted initially in Japan and the UK, and thereafter worldwide.

A Phase II study of tocilizumab was conducted in patients with systemic JIA in Japan ${ }^{49}$ and then in the UK. ${ }^{50}$ In the open-label Phase II study in Japan, 11 patients aged 2-19 years with active systemic JIA refractory to conventional therapy received escalating doses of tocilizumab. ${ }^{49}$ The study design is shown in Figure 3. Initially, all the patients received tocilizumab at a dose of $2 \mathrm{mg} / \mathrm{kg}$ body weight. When the tocilizumab dose failed to stabilize C-reactive protein level at $\leq 15 \mathrm{mg} / \mathrm{L}$ at least 5 days after the initial or second administration of tocilizumab, the dose was escalated to double that of the previous dose (ie, up to $8 \mathrm{mg} / \mathrm{kg}$ ) and was administered every 2 weeks for a total of three times. C-reactive protein was used as a surrogate marker for the tocilizumab concentration able to inhibit the actions of IL- 6 in vivo. Three of the 11 patients had neither disease flares nor increases in C-reactive protein levels after the first injection of tocilizumab $2 \mathrm{mg} / \mathrm{kg}$. Among the other eight children, who had C-reactive protein $>15 \mathrm{mg} / \mathrm{L}$ and received tocilizumab $4 \mathrm{mg} / \mathrm{kg}$, five did not have elevated C-reactive protein levels, 


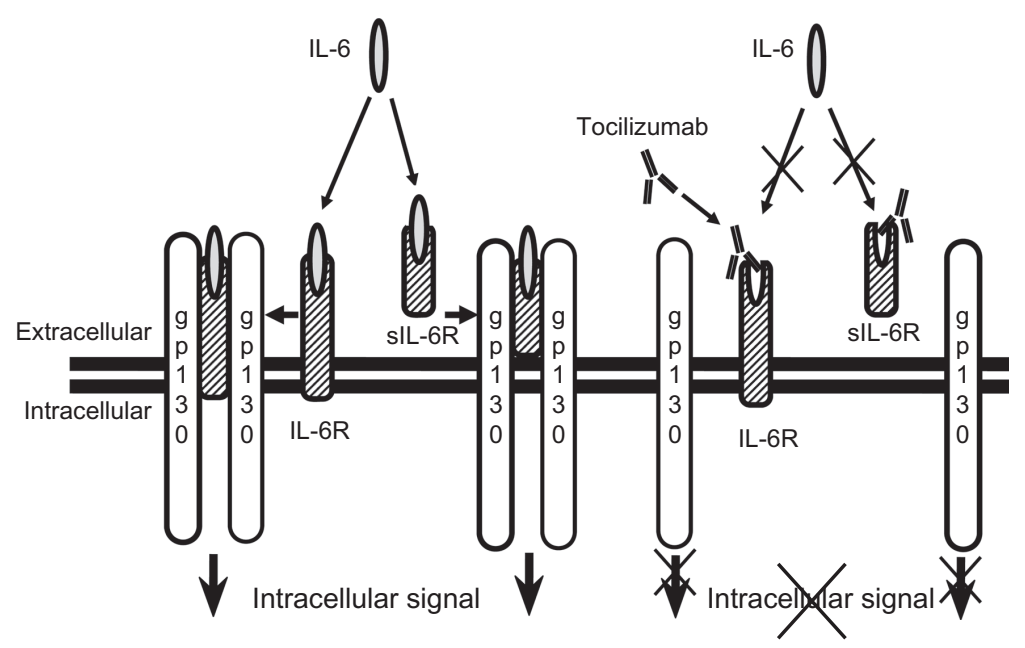

Figure 2 Tocilizumab recognizes both membrane-bound IL-6R and soluble IL-6R, and specifically inhibits binding of IL-6 to both types of IL-6Rs. Abbreviations: IL, interleukin; gP, glycoprotein; IL-6R, IL-6 receptor; sIL-6R, soluble IL-6 receptor.

while the remaining three children had increased C-reactive protein levels (two children after a single dose of $4 \mathrm{mg} / \mathrm{kg}$, and one after two doses). These three children received a further three doses of tocilizumab $8 \mathrm{mg} / \mathrm{kg}$, and thereby C-reactive protein was normalized. High-grade or quotidian fever subsided, and severe arthritis improved quickly in all 11 children after the first dose of tocilizumab.

Figure 4 shows the efficacy of tocilizumab according to the American College of Rheumatology Pediatric (ACRPed) core set of criteria for JIA. After the first infusion of tocilizumab $2 \mathrm{mg} / \mathrm{kg}$, seven (63.6\%) of the 11 children achieved a 50\% improvement in response (ACRPed50) and one patient who completed three doses of tocilizumab $2 \mathrm{mg}$ / $\mathrm{kg}$ achieved a 70\% improvement in response (ACRPed70). Among the eight children receiving tocilizumab $4 \mathrm{mg} / \mathrm{kg}$, seven (87.5\%) achieved ACRPed50, and four (50\%) achieved ACRPed70. Three patients who received three doses of tocilizumab $8 \mathrm{mg} / \mathrm{kg}$ achieved ACRPed70. These results indicate that tocilizumab $8 \mathrm{mg} / \mathrm{kg}$ dose may be adequate to control disease activity in systemic JIA.

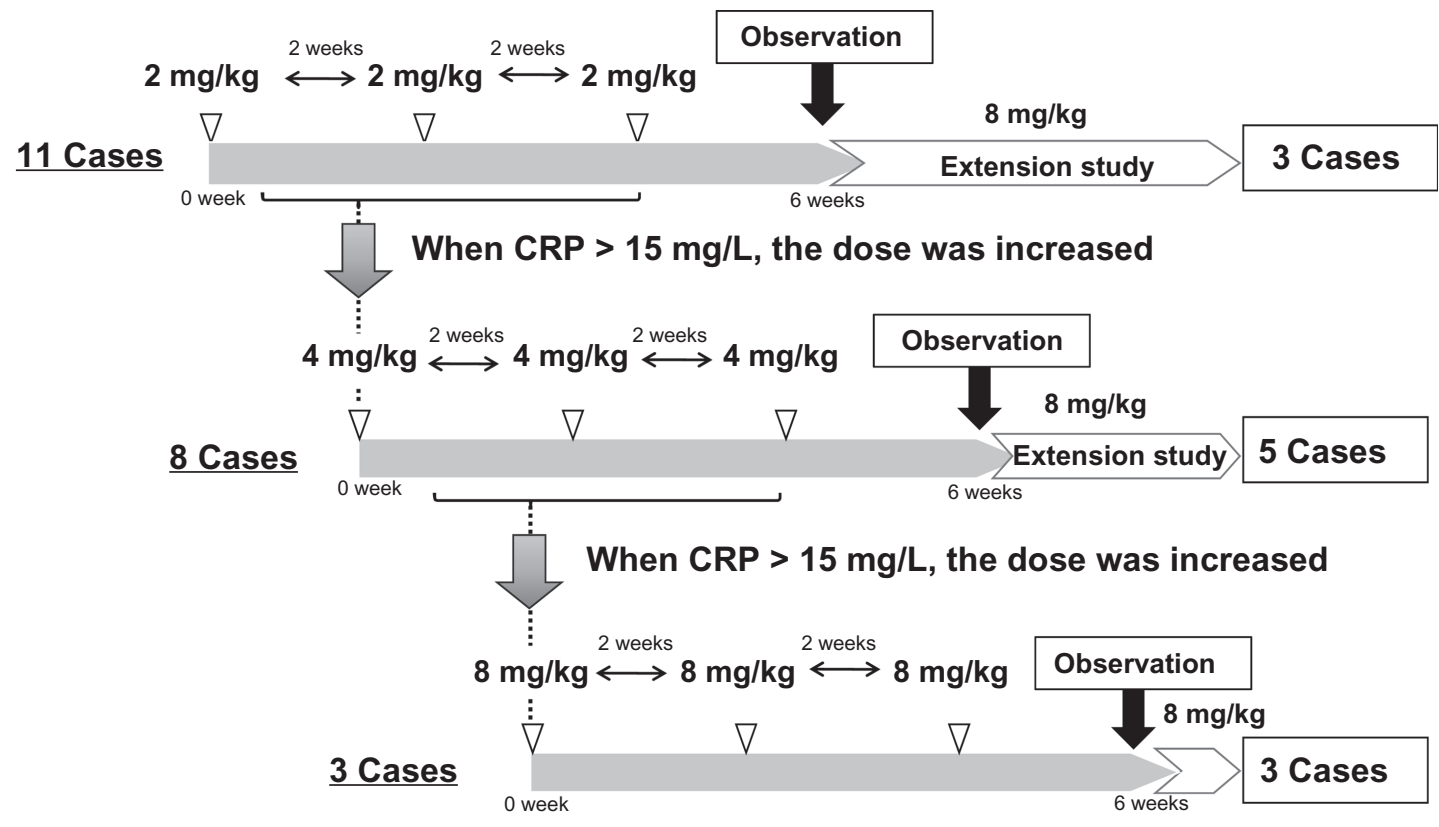

Figure 3 Design of the Phase II Japanese study of tocilizumab for patients with systemic JIA.

Note: In an open-label study, II patients with systemic JIA, who had insufficient response to the conventional therapy, were treated with tocilizumab using an intrapatient, dose-escalating schedule. ${ }^{49}$

Abbreviations: CRP, C-reactive protein; JIA, juvenile idiopathic arthritis. 


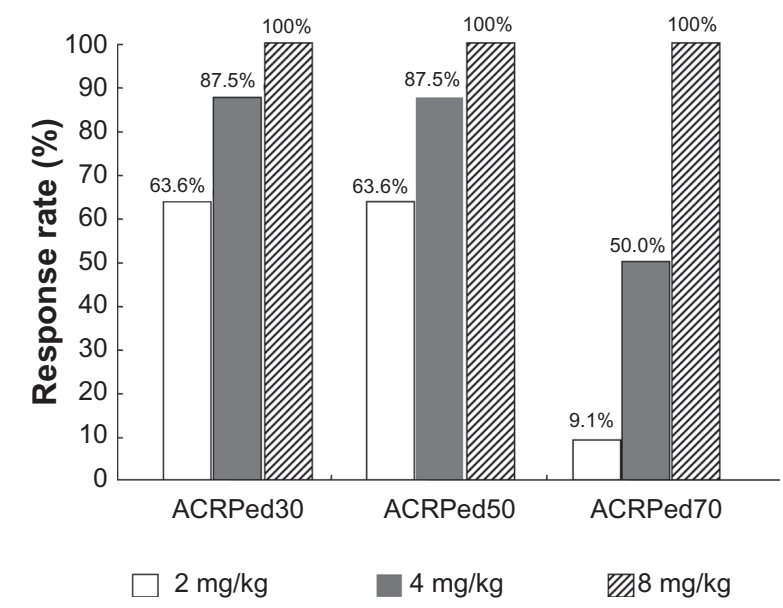

Figure 4 Efficacy of tocilizumab in patients with systemic JIA in the open-label Phase II study in Japan.

Note: The efficacy of tocilizumab was assessed according to the JIA core set of criteria. $^{49}$

Abbreviations: ACRPed, American College of Rheumatology Pediatric criteria; JIA, juvenile idiopathic arthritis.

Tocilizumab was safe and well tolerated, and no patient withdrew during the study period, and there were no deaths. The adverse events were upper respiratory tract infection (two cases, 18.2\%), pustules on the extremities (three cases, $27.2 \%$ ), and eczema (one case, 9.1\%). All laboratory abnormalities were mild, and no serious abnormalities requiring urgent treatment were noted. Increases in total cholesterol were observed in four cases (36.4\%).

An open-label Phase II single-dose trial was conducted in the UK. ${ }^{50}$ This study enrolled 18 patients with systemic JIA (white, Middle East and Asian Caucasians) who had had active disease for at least 3 months despite receiving more than $0.2 \mathrm{mg} /$ $\mathrm{kg} /$ day of prednisolone or its equivalent. They were divided into two age groups ( $2-5$ years and $6-18$ years) and randomly allocated to receive an infusion of tocilizumab $2 \mathrm{mg} / \mathrm{kg}, 4 \mathrm{mg} /$ $\mathrm{kg}$, or $8 \mathrm{mg} / \mathrm{kg}$. Three of the 18 patients were excluded due to protocol violation, so outcomes for 15 patients were evaluable for safety and efficacy. Clinical and laboratory improvements were observed at 48 hours following infusion in all patients in all dose groups. The improvement was more prolonged in the $4 \mathrm{mg} / \mathrm{kg}$ and $8 \mathrm{mg} / \mathrm{kg}$ groups than in the $2 \mathrm{mg} / \mathrm{kg}$ group, despite this being a single-dose trial. No patient was withdrawn from the study due to adverse events. The majority of adverse events were mild, and no dose-limiting toxicity was reported.

On the basis of the therapeutic benefit observed in the Phase II study, a randomized, double-blind, placebo-controlled Phase III trial was conducted in Japan. ${ }^{51}$ This study consisted of three treatment phases, ie, a 6-week open-label phase, a 12-week double-blind phase, and an open-label extension phase (Figure 5). Fifty-six patients with systemic JIA and an inadequate response to $\geq 0.2 \mathrm{mg} / \mathrm{kg}$ of prednisolone equivalent given for longer than 3 months received intravenous tocilizumab $8 \mathrm{mg} / \mathrm{kg}$ every 2 weeks for a total of three doses during the initial 6-week open-label phase. Patients who achieved an ACRPed30 response and had low C-reactive protein levels $(<5 \mathrm{mg} / \mathrm{L})$ in this initial open-label phase were randomly assigned to receive tocilizumab $8 \mathrm{mg} / \mathrm{kg}$ or placebo every 2 weeks in the double-blind phase. Thereafter, longterm safety and efficacy were investigated in the open-label extension phase of longer than 48 weeks.

At the end of the initial 6-week open-label phase, ACRPed30, 50, and 70 responses were achieved by $91 \%, 86 \%$, and $68 \%$ of patients, respectively, again indicating strong and rapid therapeutic efficacy of tocilizumab (Figure 6). During the double-blind phase, significantly more children receiving tocilizumab achieved an ACRPed30 response and C-reactive protein levels $\leq 15 \mathrm{mg} / \mathrm{L}$ compared with those receiving placebo ( $80 \%$ and $17 \%$ respectively, $P<0.0001$ ). Patients treated with tocilizumab in the double-blind phase were treated further in the long-term, open-label extension phase. In addition, patients in the placebo group who fulfilled the rescue criteria (C-reactive protein $>15 \mathrm{mg} / \mathrm{L}$ or failed ACRPed30 response) were also treated with tocilizumab in this extension phase. Efficacy was achieved within 6 weeks of restarting tocilizumab, as shown in Figure 7. At week 48, ACRPed30, 50, and 70 responses were achieved by $98 \%, 94 \%$, and $90 \%$ of patients, respectively. Moreover, 48 of 50 patients continued to receive tocilizumab treatment over 48 weeks. This good continuation rate $(96 \%$ at 48 weeks) clearly indicates that the balance of safety and efficacy is satisfactory for tocilizumab. In addition, corticosteroid doses were reduced by more than $50 \%$ in most patients after completion of the 6-week open-label and 12-week double-blind phases. Tocilizumab would be beneficial especially for patients who experience deleterious side effects from corticosteroids.

Tocilizumab was generally well tolerated, and its safety was acceptable in view of the benefit achieved. During the 6-week open-label phase, two patients withdrew because of adverse events; one for an anaphylactoid reaction and the other because of a gastrointestinal hemorrhage. The latter patient had previously had chronic diarrhea and rectal bleeding.

In the double-blind phase, frequently reported adverse events were upper respiratory tract infection and gastroenteritis, most of which were mild to moderate. The occurrence of gastroenteritis was similar between the tocilizumab and placebo groups, while upper respiratory tract infection was more frequently reported in the placebo group. One patient in each group withdrew from the study; one from the tocilizumab group who had infectious mononucleosis 


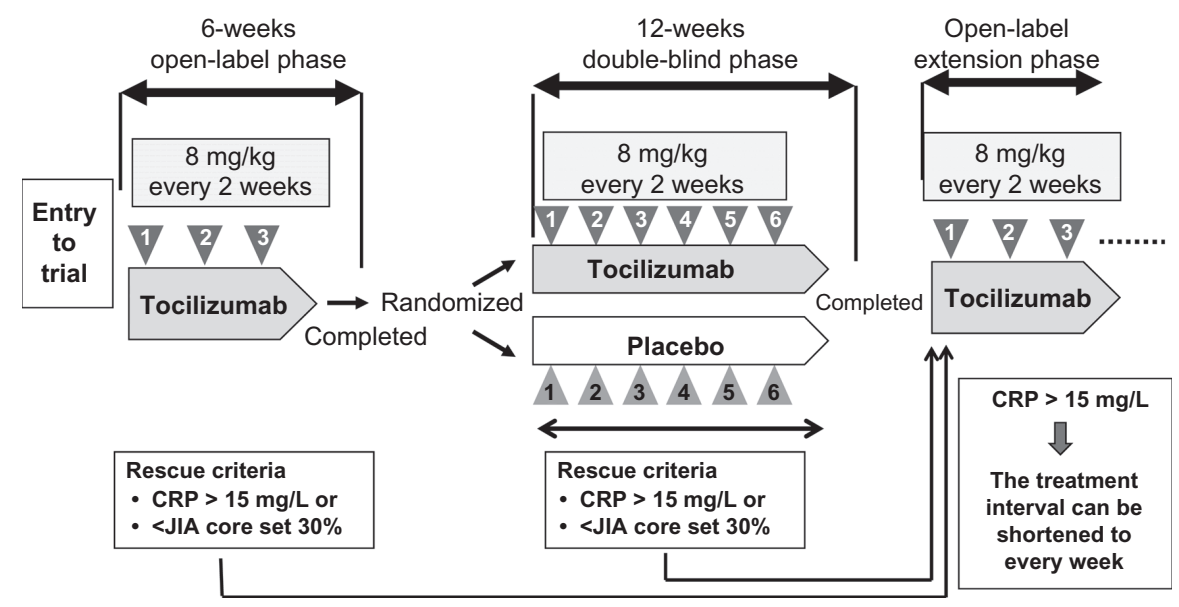

Figure 5 Study design of the Phase III Japanese study of tocilizumab for patients with systemic JIA.

Note: The Phase III Japanese trial consists of three treatment phases, ie, an initial 6-week open-label phase, a I2-week randomized, double-blind, placebo-controlled phase, and an open-label, long-term extension phase. ${ }^{51}$

Abbreviations: CRP, C-reactive protein; JIA, juvenile idiopathic arthritis.

associated with increased liver enzyme levels and neutropenia, and the other from the placebo group who developed herpes zoster after serum tocilizumab concentrations from the initial open-label phase had disappeared.

In the long-term extension phase, common adverse events in 56 patients were nasopharyngitis (33 [59\%]), upper respiratory tract infection (19 [34\%]), gastroenteritis (16 [29\%]), and bronchitis (14 [25\%]). Increases in liver function tests were observed, ie, lactate dehydrogenase (10 [18\%]), alanine aminotransferase (16 [29\%]), and aspartate aminotransferase (12 [21\%]). Increases of at least grade 2 in alanine aminotransferase and aspartate aminotransferase were recorded in 12 and eight patients, respectively. These increases were transient. Thirteen serious adverse events were reported, ie, bronchitis (two patients), gastroenteritis (two patients), and an anaphylactoid

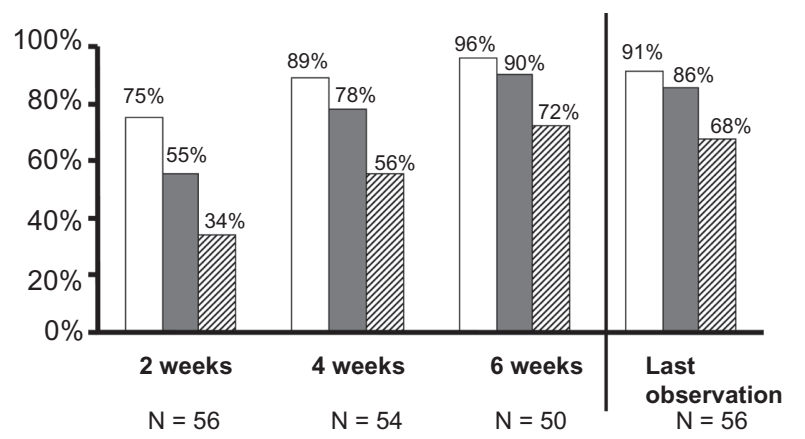

$\square$ ACRPed30 $\square$ ACRPed50 ACRPed70

Figure 6 Proportion of patients achieving ACRPed30, 50, and 70 in the initial 6-week open-label phase of the Phase III Japanese study.

Note: In the initial 6-week open-label phase, efficacy was observed as early as at 2 weeks and in a dose-dependent manner. ${ }^{51}$

Abbreviation: ACRPed, American College of Rheumatology Pediatric criteria. reaction. The cases of bronchitis and gastroenteritis resolved with antibiotics and tocilizumab treatment was continued, while the patient with the anaphylactoid reaction withdrew.

The safety of long-term treatment with tocilizumab was evaluated further in 128 patients, including those from the Phase II and Phase III Japanese studies and 61 newly recruited patients. ${ }^{52}$ The median duration of tocilizumab treatment was 78 weeks. Fourteen patients withdrew from the study, eight because of adverse events. The incidences of serious adverse events and serious infections were 37.2 and 14.5 per 100 patient-years, respectively. ${ }^{52}$ The most

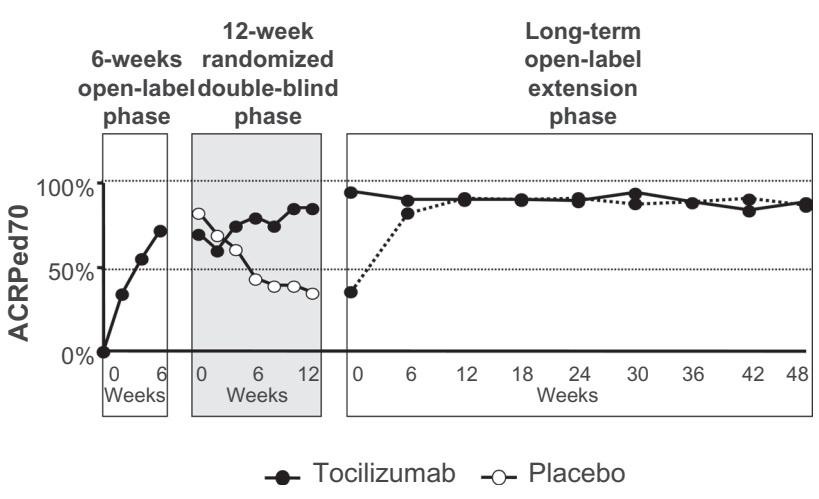

Figure 7 Proportion of patients achieving ACRPed70 in the Phase III Japanese study. Notes: In the initial 6-week open-label phase, a rapid increase in the patients who achieve ACRPed70 was observed..$^{51}$ In the double-blind phase, significantly more children receiving tocilizumab (closed circles) maintained ACRPed70 compared with those receiving placebo (open circles). In the third open-label phase, patients in the placebo group of the second phase were retreated with tocilizumab. The efficacy (closed circles with dotted line) caught up with that of the patients in the tocilizumab group of the second phase (closed circles with solid line). Copyright (C) 2008, Elsevier. Modified with permission from Yokota S, Imagawa T, Mori M, et al. Efficacy and safety of tocilizumab in patients with systemic-onset juvenile idiopathic arthritis: a randomised, double-blind, placebo-controlled, withdrawal phase III trial. Lancet. 2008;37I(96I7):998-1006. ${ }^{51}$ Abbreviation: ACRPed, American College of Rheumatology Pediatric criteria. 
frequently observed serious infections were gastroenteritis (3.8/100 patient-years) and pneumonia (3.4/100 patientyears). The long-term efficacy of tocilizumab was also confirmed, ie, ACRPed30, 50, and 70 were achieved in 94\%, $88 \%$, and $81 \%$ of patients at week $48(\mathrm{n}=78), 100 \%, 98 \%$, and $93 \%$ at week $96(\mathrm{n}=58)$, and 100\%, 100\%, and 90\% at week $144(n=41)$, respectively. Taken together with the safety data, long-term tocilizumab treatment was well tolerated and effective in patients with systemic JIA.

Based on these results, tocilizumab was approved for systemic JIA in Japan in April 2008. Thereafter, a global clinical study of tocilizumab for patients with systemic JIA was conducted and has shown robust data for efficacy and safety. ${ }^{53}$ In 2011, tocilizumab was approved for systemic JIA worldwide.

\section{Conclusion}

Tocilizumab is obviously beneficial for children with systemic JIA. The corticosteroid-sparing effect of tocilizumab is another substantial benefit, and reduction of complications, such as corticosteroid-induced growth retardation and osteoporosis is anticipated. However, we need to introduce tocilizumab treatment before the disease causes irreversible disability. The information on safety during long-term inhibition of IL-6 is still limited. Because IL-6 plays physiologically important roles, including in immune surveillance, we need to monitor safety issues carefully, especially in children. It is also still unclear whether or not tocilizumab may reduce the incidence of macrophage activation syndrome. Another issue is to investigate whether or not biologic-free remission is achievable. Future studies would resolve these issues and fully establish this agent as a therapy for systemic JIA.

\section{Disclosure}

Norihiro Nishimoto, as a medical advisor, has received a consulting fee, and as an inventor, a royalty from Chugai Pharmaceutical Co, Ltd, the company that manufactures tocilizumab. He is also on the scientific advisory board of Hoffmann-La Roche, which developed tocilizumab in collaboration with Chugai Pharmaceutical Co, Ltd.

\section{References}

1. Petty RE, Southwood TR, Manners P, et al. International League of Associations for Rheumatology classification of juvenile idiopathic arthritis: second revision, Edmonton, 2001. J Rheumatol. 2004;31(2): 390-392.

2. Mellins ED, Macaubas C, Grom AA. Pathogenesis of systemic juvenile idiopathic arthritis: some answers, more questions. Nat Rev Rheumatol. $2011 ; 7(7): 416-426$.
3. Fujikawa S, Okuni M. Clinical analysis of 570 cases with juvenile rheumatoid arthritis: results of a nationwide retrospective survey in Japan. Acta Paediatr Jpn. 1997;39(2):245-249.

4. Ravelli A, Martini A. Juvenile idiopathic arthritis. Lancet. 2007; 369(9563):767-778.

5. Moradinejad MH, Ziaee V. The incidence of macrophage activation syndrome in children with rheumatic disorders. Minerva Pediatr. 2011;63(6):459-466.

6. Kietz DA, Pepmueller PH, Moore TL. Therapeutic use of etanercept in polyarticular course juvenile idiopathic arthritis over a two year period. Ann Rheum Dis. 2002;61(2):171-173.

7. Lovell DJ, Giannini EH, Reiff A, et al. Etanercept in children with polyarticular juvenile rheumatoid arthritis. Pediatric Rheumatology Collaborative Study Group. N Engl J Med. 2000;342(11): 763-769.

8. Kietz DA, Pepmueller PH, Moore TL. Clinical response to etanercept in polyarticular course juvenile rheumatoid arthritis. J Rheumatol. 2001;28(2):360-362.

9. Lovell DJ, Reiff A, Ilowite NT, et al. Safety and efficacy of up to eight years of continuous etanercept therapy in patients with juvenile rheumatoid arthritis. Arthritis Rheum. 2008;58(5): 1496-1504.

10. Schmeling H, Mathony K, John V, Keysser G, Burdach S, Horneff G. A combination of etanercept and methotrexate for the treatment of refractory juvenile idiopathic arthritis: a pilot study. Ann Rheum Dis. 2001;60(4):410-412.

11. Lahdenne P, Vahasalo P, Honkanen V. Infliximab or etanercept in the treatment of children with refractory juvenile idiopathic arthritis: an open label study. Ann Rheum Dis. 2003;62(3):245-247.

12. Takei S, Groh D, Bernstein B, Shaham B, Gallagher K, Reiff A. Safety and efficacy of high dose etanercept in treatment of juvenile rheumatoid arthritis. J Rheumatol. 2001;28(7):1677-1680.

13. Quartier P, Taupin P, Bourdeaut F, et al. Efficacy of etanercept for the treatment of juvenile idiopathic arthritis according to the onset type. Arthritis Rheum. 2003;48(4):1093-1101.

14. Horneff G, Schmeling H, Biedermann T, et al. The German etanercept registry for treatment of juvenile idiopathic arthritis. Ann Rheum Dis. 2004;63(12):1638-1644.

15. van den Ham HJ, de Jager W, Bijlsma JW, Prakken BJ, de Boer RJ. Differential cytokine profiles in juvenile idiopathic arthritis subtypes revealed by cluster analysis. Rheumatology (Oxford). 2009;48(8): 899-905.

16. de Jager W, Hoppenreijs EP, Wulffraat NM, Wedderburn LR, Kuis W, Prakken BJ. Blood and synovial fluid cytokine signatures in patients with juvenile idiopathic arthritis: a cross-sectional study. Ann Rheum Dis. 2007;66(5):589-598.

17. Ishikawa S, Mima T, Aoki C, et al. Abnormal expression of the genes involved in cytokine networks and mitochondrial function in systemic juvenile idiopathic arthritis identified by DNA microarray analysis. Ann Rheum Dis. 2009;68(2):264-272.

18. Ramanan AV, Schneider R. Macrophage activation syndrome following initiation of etanercept in a child with systemic onset juvenile rheumatoid arthritis. J Rheumatol. 2003;30(2):401-403.

19. Pascual V, Allantaz F, Arce E, Punaro M, Banchereau J. Role of interleukin-1 (IL-1) in the pathogenesis of systemic onset juvenile idiopathic arthritis and clinical response to IL-1 blockade. J Exp Med. 2005;201(9):1479-1486.

20. Quartier P, Allantaz F, Cimaz R, et al. A multicentre, randomised, double-blind, placebo-controlled trial with the interleukin-1 receptor antagonist anakinra in patients with systemic-onset juvenile idiopathic arthritis (ANAJIS trial). Ann Rheum Dis. 2011;70(5):747-754.

21. Nishimoto N. Interleukin-6 as a therapeutic target in candidate inflammatory diseases. Clin Pharmacol Ther. 2010;87(4):483-487.

22. Yoshizaki K, Nakagawa T, Fukunaga K, Tseng LT, Yamamura Y, Kishimoto T. Isolation and characterization of B cell differentiation factor (BCDF) secreted from a human B lymphoblastoid cell line. J Immunol. 1984;132(6):2948-2954. 
23. Hirano T, Yasukawa K, Harada H, et al. Complementary DNA for a novel human interleukin (BSF-2) that induces B lymphocytes to produce immunoglobulin. Nature. 1986;324(6092):73-76.

24. Koike K, Nakahata T, Takagi M, et al. Synergism of BSF-2/interleukin 6 and interleukin 3 on development of multipotential hemopoietic progenitors in serum-free culture. J Exp Med. 1988;168(3):879-890.

25. Noma T, Mizuta T, Rosen A, Hirano T, Kishimoto T, Honjo T. Enhancement of the interleukin 2 receptor expression on $\mathrm{T}$ cells by multiple B-lymphotropic lymphokines. Immunol Lett. 1987;15(3): 249-253.

26. Okada M, Kitahara M, Kishimoto S, Matsuda T, Hirano T, Kishimoto T IL-6/BSF-2 functions as a killer helper factor in the in vitro induction of cytotoxic T cells. J Immunol. 1988;141(5):1543-1549.

27. Dong C. TH17 cells in development: an updated view of their molecular identity and genetic programming. Nat Rev Immunol. 2008;8(5):337-348.

28. Ishibashi T, Kimura H, Shikama Y, et al. Interleukin-6 is a potent thrombopoietic factor in vivo in mice. Blood. 1989;74(4):1241-1244

29. Nakajima K, Yamanaka Y, Nakae K, et al. A central role for Stat3 in IL-6-induced regulation of growth and differentiation in M1 leukemia cells. EMBO J. 1996;15(14):3651-3658.

30. De Benedetti F, Massa M, Robbioni P, Ravelli A, Burgio GR, Martini A. Correlation of serum interleukin-6 levels with joint involvement and thrombocytosis in systemic juvenile rheumatoid arthritis. Arthritis Rheum. 1991;34(9):1158-1163.

31. Crofford LJ, Kalogeras KT, Mastorakos G, et al. Circadian relationships between interleukin (IL)-6 and hypothalamic-pituitary-adrenal axis hormones: failure of IL-6 to cause sustained hypercortisolism in patients with early untreated rheumatoid arthritis. J Clin Endocrinol Metab. 1997;82(4):1279-1283.

32. Weber J, Yang JC, Topalian SL, et al. Phase I trial of subcutaneous interleukin-6 in patients with advanced malignancies. $J$ Clin Oncol. 1993;11(3):499-506.

33. Rooney M, David J, Symons J, Di Giovine F, Varsani H, Woo P. Inflammatory cytokine responses in juvenile chronic arthritis. $\mathrm{Br} \mathrm{J}$ Rheumatol. 1995;34(5):454-460.

34. Prieur AM, Roux-Lombard P, Dayer JM. Dynamics of fever and the cytokine network in systemic juvenile arthritis. Rev Rhum Engl Ed. 1996;63(3):163-170.

35. Nemeth E, Rivera S, Gabayan V, et al. IL-6 mediates hypoferremia of inflammation by inducing the synthesis of the iron regulatory hormone hepcidin. J Clin Invest. 2004;113(9):1271-1276.

36. Nakahara H, Song J, Sugimoto M, et al. Anti-interleukin-6 receptor antibody therapy reduces vascular endothelial growth factor production in rheumatoid arthritis. Arthritis Rheum. 2003;48(6):1521-1529.

37. Tamura T, Udagawa N, Takahashi N, et al. Soluble interleukin-6 receptor triggers osteoclast formation by interleukin 6. Proc Natl Acad Sci US A. 1993;90(24):11924-11928.

38. Bennett AE, Silverman ED, Miller JJ 3rd, Hintz RL. Insulin-like growth factors I and II in children with systemic onset juvenile arthritis. J Rheumatol. 1988;15(4):655-658.

39. Allen RC, Jimenez M, Cowell CT. Insulin-like growth factor and growth hormone secretion in juvenile chronic arthritis. Ann Rheum Dis. 1991;50(9):602-606.
40. De Benedetti F, Alonzi T, Moretta A, et al. Interleukin 6 causes growth impairment in transgenic mice through a decrease in insulin-like growth factor-I. A model for stunted growth in children with chronic inflammation. J Clin Invest. 1997;99(4):643-650.

41. Lieskovska J, Guo D, Derman E. IL-6-overexpression brings about growth impairment potentially through a $\mathrm{GH}$ receptor defect. Growth Horm IGF Res. 2002;12(6):388-398.

42. Lieskovska J, Guo D, Derman E. Growth impairment in IL-6overexpressing transgenic mice is associated with induction of SOCS3 mRNA. Growth Horm IGF Res. 2003;13(1):26-35.

43. De Benedetti F, Meazza C, Oliveri M, et al. Effect of IL-6 on IGF binding protein-3: a study in IL-6 transgenic mice and in patients with systemic juvenile idiopathic arthritis. Endocrinology. 2001;142(11):4818-4826.

44. De Benedetti F, Pignatti P, Gerloni V, et al. Differences in synovial fluid cytokine levels between juvenile and adult rheumatoid arthritis. J Rheumatol. 1997;24(7):1403-1409.

45. Fishman D, Faulds G, Jeffery R, et al. The effect of novel polymorphisms in the interleukin-6 (IL-6) gene on IL-6 transcription and plasma IL-6 levels, and an association with systemic-onset juvenile chronic arthritis. J Clin Invest. 1998;102(7):1369-1376.

46. Ogilvie EM, Fife MS, Thompson SD, et al. The $-174 \mathrm{G}$ allele of the interleukin-6 gene confers susceptibility to systemic arthritis in children: a multicenter study using simplex and multiplex juvenile idiopathic arthritis families. Arthritis Rheum. 2003;48(11):3202-3206.

47. Kishimoto T, Akira S, Taga T. Interleukin-6 and its receptor: a paradigm for cytokines. Science. 1992;258(5082):593-597.

48. Scheller J, Ohnesorge N, Rose-John S. Interleukin-6 transsignalling in chronic inflammation and cancer. Scand J Immunol. 2006;63(5):321-329.

49. Yokota S, Miyamae T, Imagawa T, et al. Therapeutic efficacy of humanized recombinant anti-interleukin-6 receptor antibody in children with systemic-onset juvenile idiopathic arthritis. Arthritis Rheum. 2005;52(3):818-825.

50. Woo P, Wilkinson N, Prieur AM, et al. Open label phase II trial of single, ascending doses of MRA in Caucasian children with severe systemic juvenile idiopathic arthritis: proof of principle of the efficacy of IL-6 receptor blockade in this type of arthritis and demonstration of prolonged clinical improvement. Arthritis Res Ther. 2005;7(6):R1281-R1288.

51. Yokota S, Imagawa T, Mori M, et al. Efficacy and safety of tocilizumab in patients with systemic-onset juvenile idiopathic arthritis: a randomised, double-blind, placebo-controlled, withdrawal phase III trial. Lancet. 2008;371(9617):998-1006.

52. Yokota S, Imagawa T, Miyamae T, et al. Long-term safety and efficacy of tocilizumab in patients with systemic juvenile idiopathic arthritis (JIA) under the extension and long-term trials. Arthritis Rheum. 2008; 58 Suppl:S631.

53. De Benedetti F, Brunner H, Allen R, et al. Tocilizumab is efficacious in patients with systemic juvenile idiopathic arthritis across baseline demographic and disease characteristics and prior/baseline treatments: 52-week data from a phase 3 clinical trial. Arthritis Rheum. 2011; 63 Suppl:S1029.
Open Access Rheumatology Research and Reviews

\section{Publish your work in this journal}

Open Access Rheumatology Research and Reviews is an international, peer-reviewed, open access journal, publishing all aspects of clinical and experimental rheumatology in the clinic and laboratory including the following topics: Pathology, pathophysiology of rheumatological diseases; Investigation, treatment and management of rheumatological

\section{Dovepress}

diseases; Clinical trials and novel pharmacological approaches for the treatment of rheumatological disorders. The manuscript management system is completely online and includes a very quick and fair peerreview system, which is all easy to use. Visit http://www.dovepress.com/ testimonials.php to read real quotes from published authors. 